\title{
Recurrent Caterpillar-like Arachnoid Cysts Following Initial Resection: A Unique Presentation of a Disorder Where the Limits of Modern Medicine Are Reached
}

\author{
Sean W. Kaloostian ${ }^{1}$, Tara K. Vartanian ${ }^{2}$, Christ Ordookhanian ${ }^{3}$, Talia Vartanian ${ }^{4}$, Paul E. Kaloostian ${ }^{1}$ \\ 1. Neurological Surgery, Haider Spine Center, Riverside, USA 2. Internal Medicine, White Memorial Medical Center, Los \\ Angeles, USA 3. Biochemistry, University of California, Riverside, USA 4. Physical Medicine and Rehabilitation, \\ University of Southern California, Pomona, USA
}

Corresponding author: Paul E. Kaloostian, pkaloostian@gmail.com

\begin{abstract}
Of the many emergent neurological cases presenting to the emergency department (ED) and operating room (OR) for resection, arachnoid cysts are amongst one of the rarer pathologies. The proper resection of arachnoid cysts has substantially decreased the risk of recurrence. Current medicinal and surgical approaches have been refined over the years and prove to be successful for many patients. Where current practices begin to fail is during the treatment of complex and rare cases, such as the one presented in this manuscript. The commonly accepted surgical practices that were utilized to aid in the management of our patient, who initially presented with a simple arachnoid cyst, unexpectedly resulted in the further development of additional arachnoid cysts, a very rare occurrence, and a complication that should be discussed amongst all specialists in the hope of identifying more focused, novel, and less-invasive approaches to cyst removal and recurrence prevention.
\end{abstract}

Received 11/27/2018

Review began 12/21/2018 Review ended 01/22/2019 Published 01/23/2019

(c) Copyright 2019

Kaloostian et al. This is an open access article distributed under the terms of the Creative Commons Attribution License CC-BY 3.0., which permits unrestricted use, distribution, and reproduction in any medium, provided the original author and source are credited.
Categories: Emergency Medicine, Medical Education, Quality Improvement

Keywords: arachnoid cyst, caterpillar-like, craniospinal, neuraxis, recurrence, limitations, educational

\section{Introduction}

Arachnoid cysts are congenital disorders visually characterized as benign lesions physiologically represented by herniations of the arachnoid membrane through pre-existing and/or acquired dural defects [1-2]. In this report, we present an extremely rare case of an individual with contiguous pan-neuraxis craniospinal arachnoid cysts. The patient is a 49 -year-old Hispanic female who initially presented with worsening right lower extremity radicular pain and urinary retention. The examination was consistent with myelopathy, and imaging revealed several contiguous cysts communicating within the subarachnoid space through loculated membranes. She successfully underwent multiple thoracic and lumbar laminectomies, resulting in the complete resolution of preoperative symptoms. After an extensive review of the literature, our patient represents a novel case of recurrent, caterpillar-like arachnoid cyst pathology of the entire spine.

\section{Case Presentation}

A 49-year-old Hispanic female presented to the clinic one month following a widening of a previous laminectomy for the resection of a lumbar (L) level four to five arachnoid cyst, with worsening right lower extremity radicular pain and urinary retention. The patient reported bilateral lower extremity pain but predominantly focused on the worsening right-sided radicular pain that resulted in a burning sensation down into the sole of her foot. The agonizing pain was complicating our patient's ability to walk and urinate, as the need to strain in order to get proper function resulted in increased pain down in the right leg. She did, however, deny urinary incontinence, fecal incontinence, or motor weakness in the lower extremities.

Magnetic resonance imaging (MRI) was obtained (Figures 1-2) and revealed caterpillar-like pan-neuraxis arachnoid cysts that initially appeared to be intradurally distributed throughout her spinal canal. 


\section{Cureus}

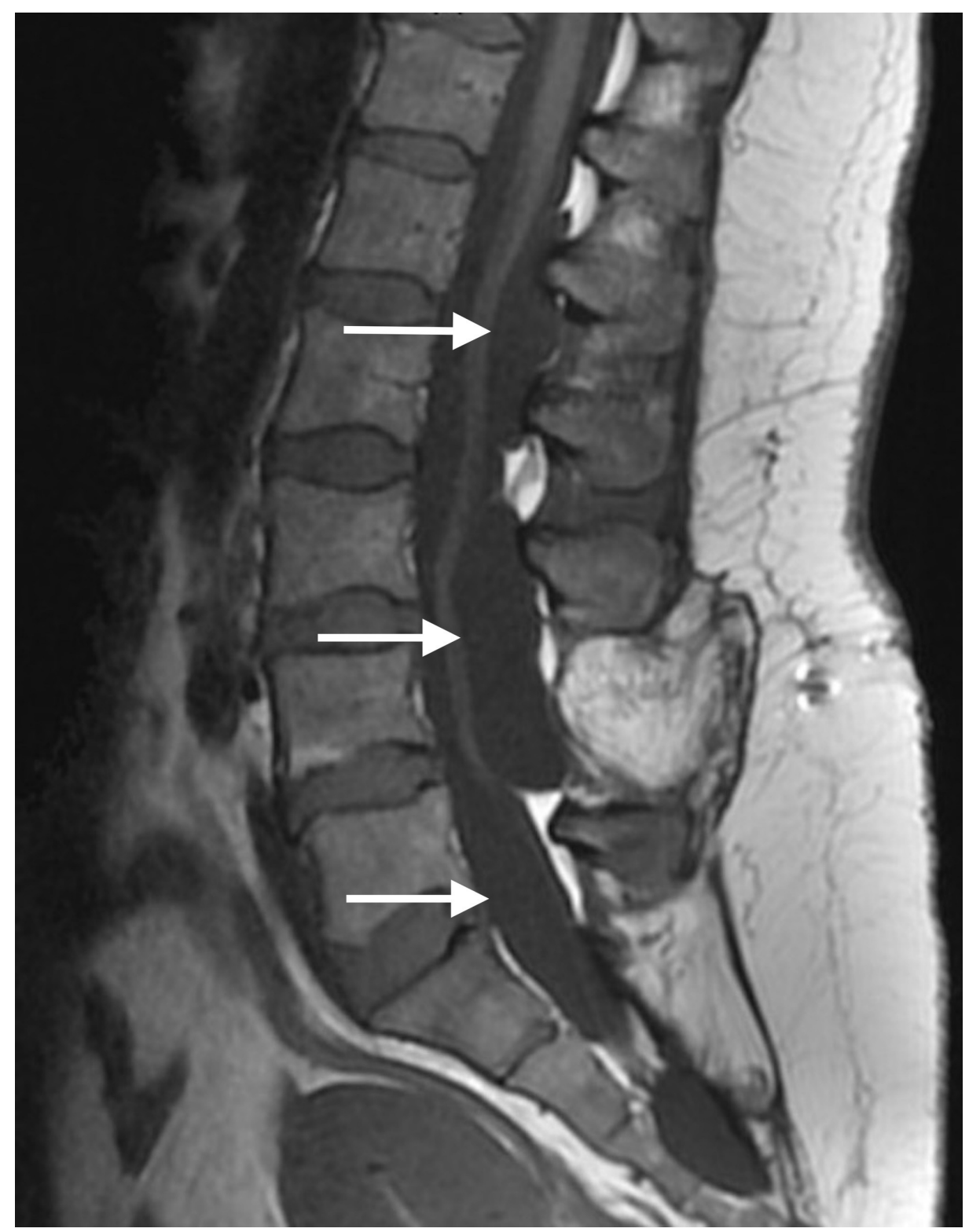

FIGURE 1: Sagittal T1 FSE MRI of the Spine

FSE: fast spin echo; MRI: magnetic resonance imaging 


\section{Cureus}

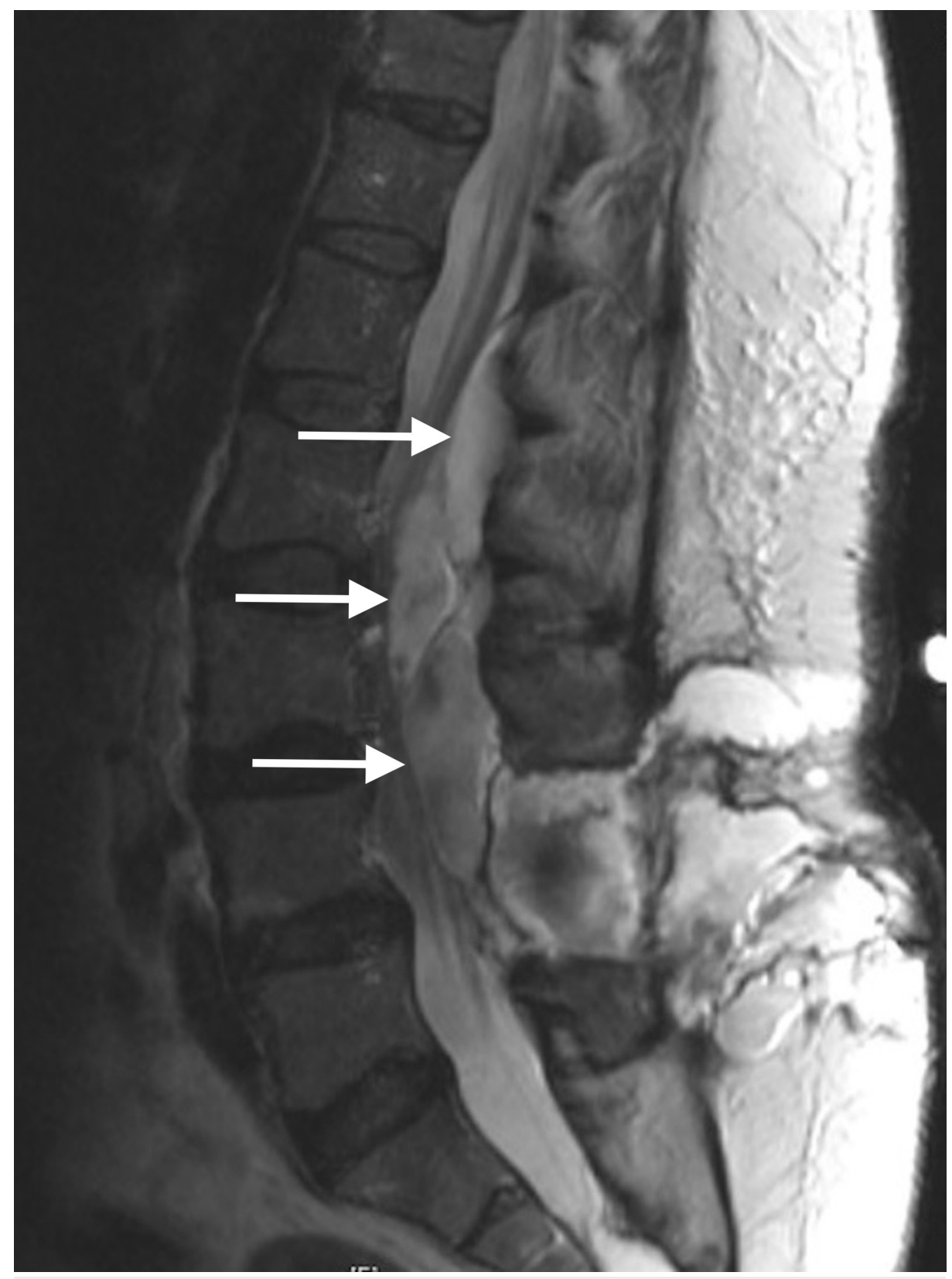

\section{FIGURE 2: Sagittal T2 TSE MRI of the Spine}

TSE: turbo spin echo; MRI: magnetic resonance imaging

Two were visualized in the thoracic region, one extending from thoracic (T) level one to four and the other extending from thoracic level four to six. Two were localized to the lumbar region, one extending from lumbar level one to three, and the other extending from lumbar level four to five. Upon completion of a thorough neurological exam, our patient had full strength in both her upper and lower extremities without any pronator drift; a sensory exam indicated an intact system. However, on more special testing, we were able to elicit a positive straight leg raise on the right. Reflexes in the upper extremities were normal while bilateral patellar and Achilles reflexes were three-plus, suggesting myelopathy.

MRI performed one week prior (Figure 3) showed the arachnoid cyst at thoracic level four to six. It appeared to be enlarging and exerting a mass effect on the spinal cord, causing compression with flattening of the cord at thoracic level five. 


\section{Cureus}

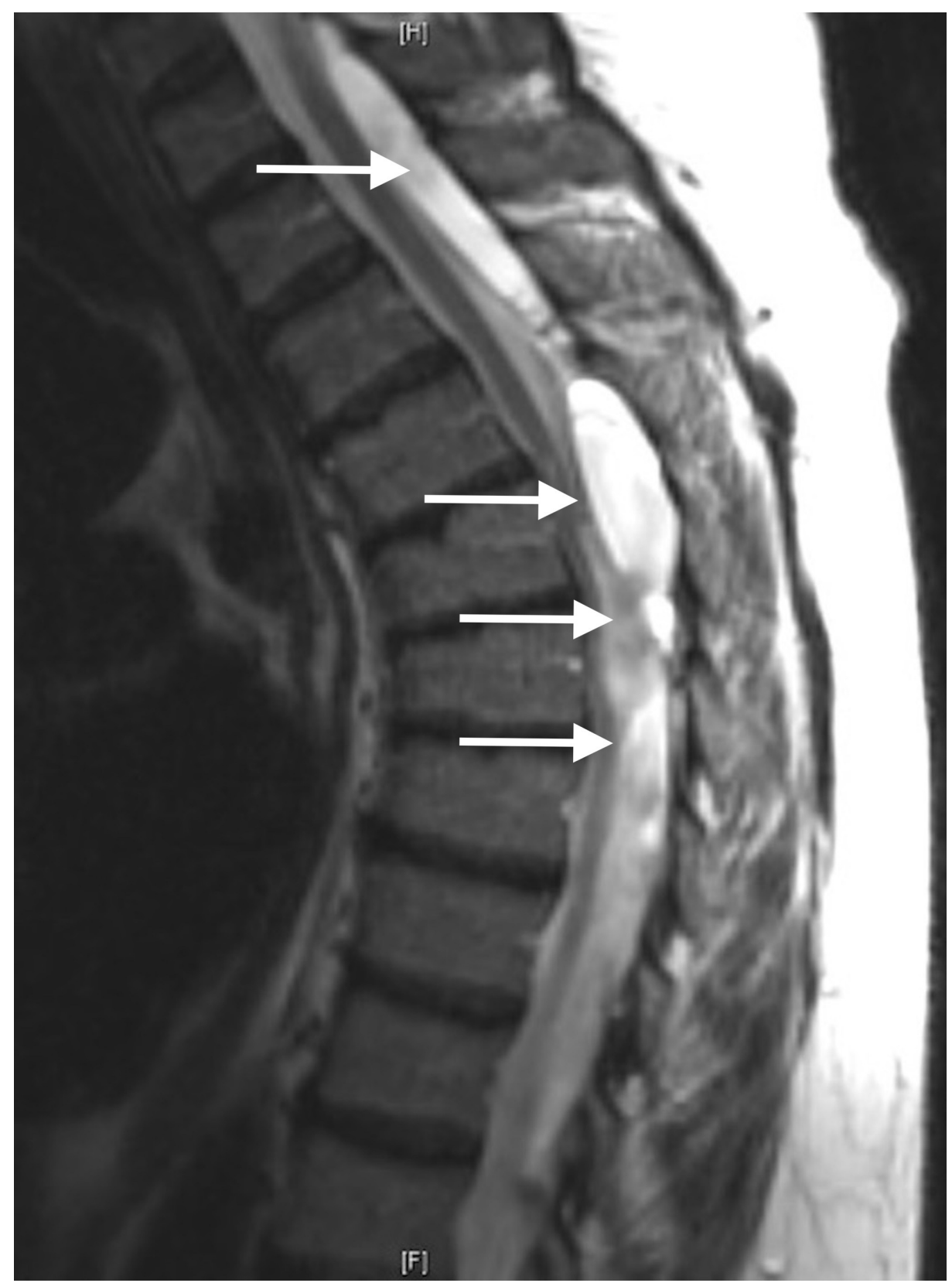

FIGURE 3: Sagittal T2 TSE MRI of the Thoracic Spine

TSE: turbo spin echo; MRI: magnetic resonance imaging

The arachnoid cyst at lumbar level one to three was noted to be enlarging and compressing the descending nerve roots more on the right side. A computed tomography (CT) myelogram was obtained the following day and revealed all caterpillar-like arachnoid cysts to be posterior and communicating separately with the subarachnoid space. Due to the patient's difficulty with normal daily function, severe pain, and advanced myelopathy, she was brought urgently to the operating room the day after the CT myelogram was obtained for surgical intervention.

A thoracic level four to six laminectomy was planned with the excision of an intradural arachnoid cyst with dural repair. In addition, a separate incision was made for a lumbar level one to three laminectomy, with the excision of an intradural arachnoid cyst with complex dural repair at lumbar level three, the site where the patient had a prior dural defect and was found to be leaking cerebrospinal fluid (CSF). Surprisingly, at surgery, the cysts at thoracic level four to six and lumbar level one to three were noted to be extradural in nature. In both areas, we were able to work around the curved edges of the superior mass and detect the area connecting to the midline of the dura where a small area of communication within the dura was visualized. At both the thoracic level four to six and lumbar level one to three, the caterpillar-like cysts were excised epidurally and the dura was closed watertight. Postoperative MRI (Figures 4-5) revealed the 


\section{Cureus}

unroofing of the thoracic level four to six and lumbar level one to three cysts, improvement in the caliber of the thecal sac and spinal cord, and resolution of the previously noted CSF leak.

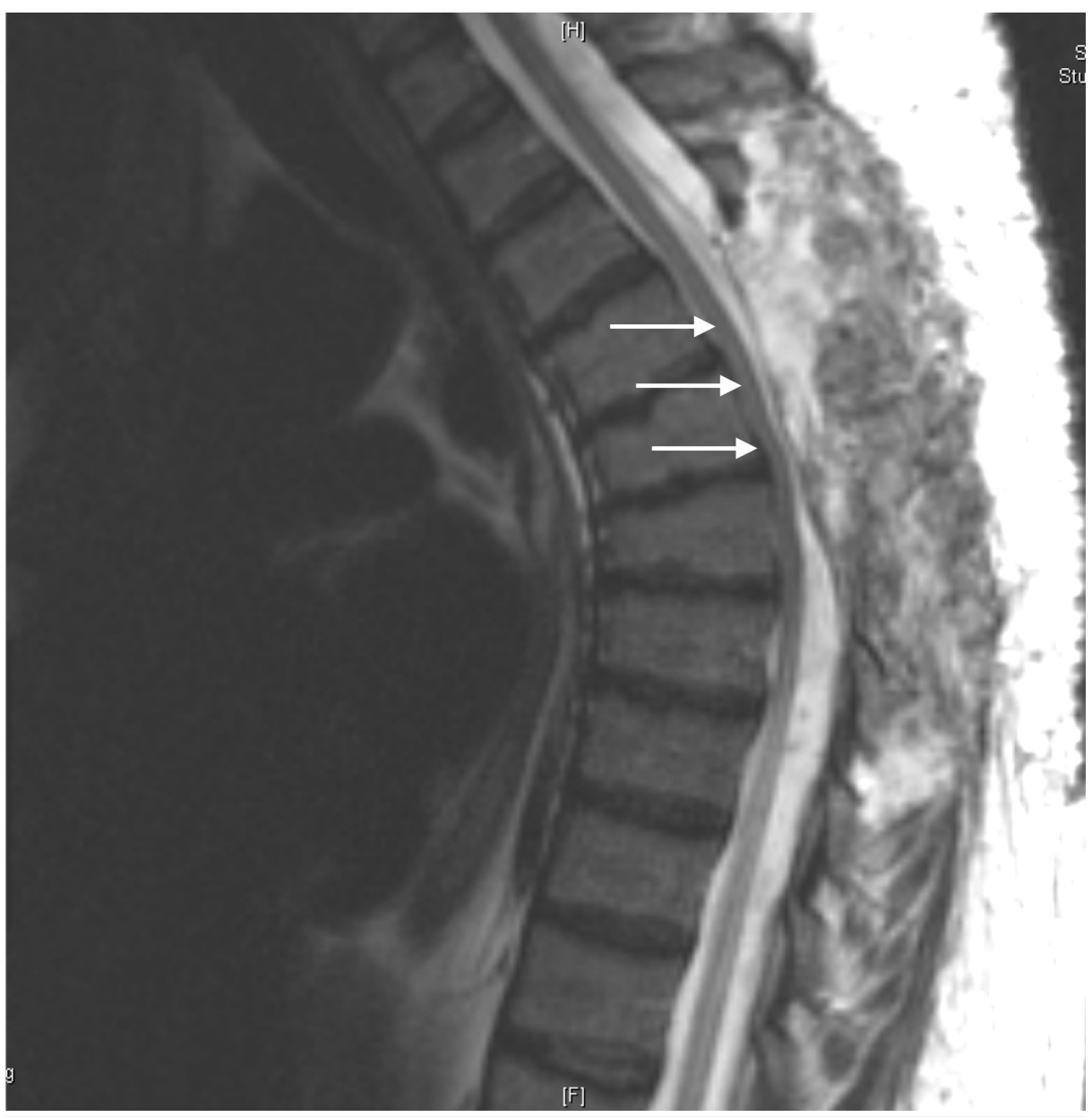

FIGURE 4: Post-Operative Sagittal MRI of Thoracic Spine 


\section{Cureus}

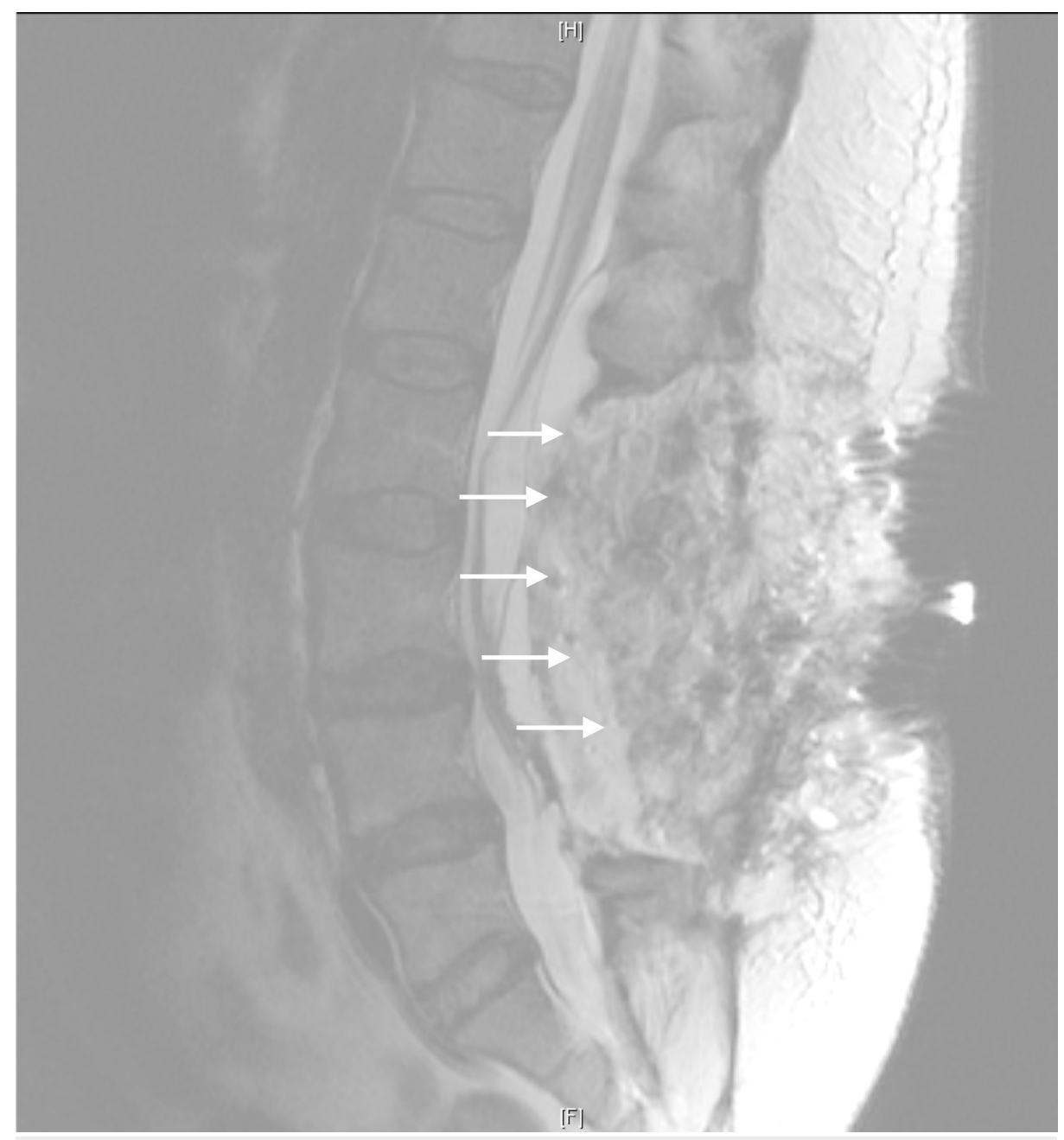

FIGURE 5: Post-Operative Sagittal MRI of Lumbar Spine

The patient's postoperative course was encouraging, and she was discharged on postoperative Day 5. At the one and six-month follow-up visits, the patient endorsed the improvement of preoperative symptoms, including the resolution of right lower extremity radicular pain, urinary retention, and headaches.

\section{Discussion}

Extradural arachnoid cysts are CSF) containing cavities that are the result of the herniation of the arachnoid membrane through dural defects [3-4]. The prevalence of extradural arachnoid cysts is most likely in the thoracic cord region $65 \%$ of the time, presenting in the lumbar region $25 \%$ of the time, $6 \%$ in the sacral region, and $4 \%$ in the cervical cord region [5-6]. Adolescents tend to present with extradural cysts in the thoracic cord region while adults in their 30s and 40s typically present with lumbar or lumbosacral cysts $[2,7]$. Through unknown mechanisms, it is expected that approximately $50 \%$ of extradural arachnoid cysts will extend into the neural foramina, an opening between the vertebra where spinal nerve roots enter and exit [1,8-9]. Additionally, these particular cysts are twice as common in males and more likely to be symptomatic in the second decade of life [9-10]. More often than not, arachnoid cysts are asymptomatic and incidentally found through MR imaging, making it challenging to assess their true incidence, although they have been reported to represent $1 \%-3 \%$ of space-occupying lesions within the spinal canal [10].

Currently, there exist only a handful of adult and pediatric cases that are well documented in the literature [11-18]. However, the clinical presentation of caterpillar-like cysts throughout the pan neuraxis are extremely rare, this being the first piece of literature to describe the pathology. Our patient presented with a unique case given the recurrence of previously resected intradural cysts in the lumbar spine, in addition to the development of additional caterpillar-like cysts along the pan neuraxis causing severe neurological deficits. The pathophysiology behind the development of these lesions is still unknown and may be in part due to CSF dysregulation. To date, the best treatment, regardless of presentation, remains complete tumor resection for symptomatic cysts, which has been prevalent throughout the literature for solitary cysts [1920]. However, our case demonstrates a rare scenario where complete surgical resection initially failed and thus resulted in more severe loculated pan neuraxis caterpillar-like cysts for the patient. Of key importance 
in our patient's case was to conduct the additional screenings to determine vascularity and the CSF dynamics of each of the cysts prior to resection, which allowed for more precise surgical intervention with tactical entry points to maximize positive outcomes.

\section{Conclusions}

Our study demonstrates the ability of such arachnoid cysts to not only form throughout the craniospinal axis but also to form multiple simultaneous loculated cysts in this region, hence the term caterpillar-like arachnoid cysts. In treating such patients, appropriate diagnostic and surgical modalities, as described above, are recommended, including the need for the imaging of the entire craniospinal axis to identify other, associated cysts that may need to be observed or treated. We believe this information will be helpful in the field of neurosurgery in terms of changing current diagnostic methods and managing patients who present with arachnoid cysts of the spine.

\section{Additional Information \\ Disclosures}

Human subjects: Consent was obtained by all participants in this study. Conflicts of interest: In compliance with the ICMJE uniform disclosure form, all authors declare the following: Payment/services info: All authors have declared that no financial support was received from any organization for the submitted work. Financial relationships: All authors have declared that they have no financial relationships at present or within the previous three years with any organizations that might have an interest in the submitted work. Other relationships: All authors have declared that there are no other relationships or activities that could appear to have influenced the submitted work.

\section{References}

1. Garg K, Borkar SA, Kale SS, Sharma BS: Spinal arachnoid cysts - our experience and review of literature . Br J Neurosurg. 2017, 31:172-178. 10.1080/02688697.2016.1229747

2. Hughes G, Ugokwe K, Benzel EC: A review of spinal arachnoid cysts . Cleve Clin J Med. 2008, 75:311-315.

3. de Oliveira RS, Amato MCM, Santos MV, Simão GN, Machado HR: Extradural arachnoid cysts in children. Childs Nerv Syst. 2007, 23:1233-1238. 10.1007/s00381-007-0414-6

4. Alugolu R, Arradi V, Sahu BP: Intramedullary arachnoid cyst in an adult: case report and review . Asian J Neurosurg. 2016, 11:77-80. 10.4103/1793-5482.145054

5. Basaldella L, Orvieto E, Dei Tos AP, Della Barbera M, Valente M, Longatti P: Causes of arachnoid cyst development and expansion. Neurosurg Focus. 2007, 22:4.

6. Samartzis D, Gillis CC, Shih P, O'Toole JE, Fessler RG: Intramedullary spinal cord tumors: part Iepidemiology, pathophysiology, and diagnosis. Global Spine J. 2015, 5:425-435. 10.1055/s-0035-1549029

7. Tureyen K, Senol N, Sahin B, Karahan N: Spinal extradural arachnoid cyst. Spine J. 2009, 9:10-15. 10.1016/j.spinee.2009.03.006

8. Choi SW, Seong HY, Roh SW: Spinal extradural arachnoid cyst . J Korean Neurosurg Soc. 2013, 54:355-358. 10.3340/jkns.2013.54.4.355

9. Cho HY, Lee SH, Kim ES, Eoh W: Symptomatic large spinal extradural arachnoid cyst: a case report . Korean J Spine. 2015, 12:217-220.

10. Liu JK, Cole CD, Kan P, Schmidt MH: Spinal extradural arachnoid cysts: clinical, radiological, and surgical features. Neurosurg Focus. 2007, 22:1-5. 10.3171/foc.2007.22.2.6

11. Marbacher S, Barth A, Arnold M, Seiler RW: Multiple spinal extradural meningeal cysts presenting as acute paraplegia. Case report and review of the literature. J Neurosurg. 2007, 6:465-472. 10.3171/spi.2007.6.5.465

12. Suryaningtyas W, Arifin M: Multiple spinal extradural arachnoid cysts occurring in a child. Case report . I Neurosurg. 2007, 106:158-161. 10.3171/ped.2007.106.2.158

13. Yabuki S, Kikuchi S: Multiple extradural arachnoid cysts: report of two operated cousin cases . Spine. 2007, 32:585-588. 10.1097/BRS.0b013e31814b8488

14. Ergun T, Lakadamyali H: Multiple extradural spinal arachnoid cysts causing diffuse myelomalacia of the spinal cord. Neurologist. 2009, 15:347-350. 10.1097/NRL.0b013e318194022e

15. Kumar S, Desai A, Bhatia L, Garg A: Multiple spinal arachnoid cysts in a child . Pediatr Neurol. 2016, 55:7677. 10.1016/j.pediatrneurol.2015.03.007

16. Bond AE, Zada G, Bowen I, McComb JG, Krieger MD: Spinal arachnoid cysts in the pediatric population: report of 31 cases and a review of the literature. J Neurosurg Pediatr. 2012, 9:432-441. 10.3171/2012.1.PEDS11391

17. Nayak R, Chaudhuri A, Sadique S, Attry S: Multiple spinal extradural arachnoidal cysts: an uncommon cause of thoracic cord compression. Asian J Neurosurg. 2017, 12:321-323. 10.4103/1793-5482.150004

18. Petridis AK, Doukas A, Barth H, Mehdorn HM: Spinal cord compression caused by idiopathic intradural arachnoid cysts of the spine: review of the literature and illustrated case. Eur Spine J. 2010, 19:124-129. 10.1007/s00586-009-1156-9

19. Klekamp J, Samii M: Surgical results of spinal meningiomas. Acta Neurochir Suppl. 1996, 65:77-81.

20. Klekamp J: How should syringomyelia be defined and diagnosed? . World Neurosurg. 2018, 111:729-745. 10.1016/j.wneu.2017.12.156 